\title{
Tensile and Creep Characteristics of Sputtered Gold-Tin Eutectic Solder Film Evaluated by XRD Tensile Testing
}

\author{
Takahiro Namazu*, Hideki Takemoto and Shozo Inoue \\ Division of Mechanical Systems, Department of Mechanical and Systems Engineering, \\ University of Hyogo, 2167 Shosha, Himeji, Hyogo 671-2201, Japan
}

(Received February 5, 2009; accepted August 11, 2009)

Key words: Au-Sn film, sputtering, X-ray diffraction, tensile test, creep test, Young's modulus, Poisson's ratio

In this paper, we describe the elastic-inelastic mechanical property measurements of a gold-tin ( $\mathrm{Au}-\mathrm{Sn})$ eutectic solder film. Dual-source direct-current (dc) magnetron sputtering was employed to deposit a Au-20 weight \% (wt.\%) Sn film. A uniaxial tensile test with in situ X-ray diffraction (XRD) analysis was performed at temperatures ranging from room temperature (RT) to $373 \mathrm{~K}$. The XRD tensile test enabled us to directly measure out-of-plane strain in the Au-Sn film specimen for Poisson's ratio determination. The mean Young's modulus and Poisson's ratio at RT were found to be $51.3 \mathrm{GPa}$ and 0.288 , respectively, which were lower than the bulk values. The Young's modulus decreased with an increase in temperature, whereas the Poisson's ratio showed no change with temperature. In addition, a creep test was carried out at various stresses and temperatures. The steady-state creep deformation behavior could be estimated on the basis of Norton's law. Information on the tensile and creep characteristics would be useful in designing Au-Sn-film-bonded microjoints used in micro-electromechanical systems (MEMS).

\section{Introduction}

In package assemblies for micro-electromechanical systems (MEMS), a soldered joint plays a key role as a significant electrical and mechanical interconnection. Several types of solder film deposited by sputtering are used to bond microelements made of silicon or glass. The reliability of package assemblies largely depends on the reliability of the solder film joints because such joints have a relatively low structure compliance compared with the jointed microelements. Therefore, the precise evaluation of a solder film's mechanical behavior is one of the significant issues for the development of reliable MEMS soldering packages.

"Corresponding author: e-mail: namazu@eng.u-hyogo.ac.jp 
To date, the investigation of the mechanical behavior of solder materials has been carried out using uniaxial tensile, torsion, and compression tests. ${ }^{(1-4)}$ The uniaxial tensile test, which is a common material test method for the mechanical characterization of materials, is often employed to study the elastic, inelastic, and creep properties of solder materials with milliscale dimensions. If a specimen has a solder-jointed section, bond strength can be estimated by the uniaxial tensile test. However, when the target material is a solder film, a mechanical test is very difficult to perform accurately because there are technical difficulties in preparing thin-film specimens, in applying a tensile force to the specimen, and in detecting a very small physical response from the film during the test.

To characterize a solder film material, we have conducted the uniaxial tensile test with in situ X-ray diffraction (XRD) analysis. The combination of uniaxial tensile test and in situ XRD analysis enables us to examine the mechanical characteristics of materials with atomic-level resolution. ${ }^{(5-11)}$ The objective of this work is to investigate the tensile and creep properties of a sputtered $\mathrm{Au}$-Sn eutectic solder film at temperatures ranging from RT to $373 \mathrm{~K}$. Young's modulus and Poisson's ratio were evaluated using the XRD tensile test. A creep test was also performed in order to obtain creep parameters utilized for the estimation of creep curves for the Au-Sn solder film.

\section{Experimental Procedure}

\subsection{Deposition of Au-Sn solder film}

$\mathrm{Au}-\mathrm{Sn}$ eutectic solder films were deposited using a dual-source direct-current (dc) magnetron sputtering apparatus developed by the authors. The composition of the films was set to be 80 weight \% (wt.\%) and 20 wt.\% for Au and Sn, respectively, by controlling the electric power for each sputtering gun. During deposition, a fixed distance of 95 $\mathrm{mm}$ between the target and substrate was maintained, and pure argon, maintained at a constant pressure of $0.2 \mathrm{~Pa}$, was employed as the working gas. Substrate temperature was not controlled. All the Au-Sn films were deposited onto the diced single-crystal silicon $(\mathrm{Si})$ chip covered with a silicon oxide $\left(\mathrm{SiO}_{x}\right)$ thin layer originating from a thermal oxidation process. Before the deposition, the Si chip was rinsed in a solution of sulfuric acid and hydrogen peroxide to remove organic matter on the chip.

Using XRD and scanning electron microscope analyses, all the Au-Sn films we prepared were determined to have a columnar structure of polycrystal. The diameter of each column was roughly estimated to be $0.5 \mu \mathrm{m}$. While annealing for $2 \mathrm{~h}$ at $516 \mathrm{~K}$, the shape of the obtained XRD spectrum gradually changed, i.e., peak intensity gradually increased whereas peak width decreased. This indicates that the Au-Sn columns gradually changed into polycrystal grains. After annealing for $2 \mathrm{~h}$, such changes were hardly observed because the film structure and its crystallinity were stabilized. Therefore, annealing for $2 \mathrm{~h}$ was conducted in the fabrication process of a specimen.

\subsection{Specimen}

Figure 1 shows a schematic of the process flow for fabricating a Au-Sn film specimen along with a photograph. We used a Si wafer as the starting material, which consisted of a $380-\mu$ m-thick $\mathrm{Si}$ wafer with a $1-\mu$ m-thick $\mathrm{SiO}_{x}$ film layer produced by wet thermal 
(1) $\mathrm{Si}$ wafer with $\mathrm{SiO}_{\mathrm{x}}$ layer

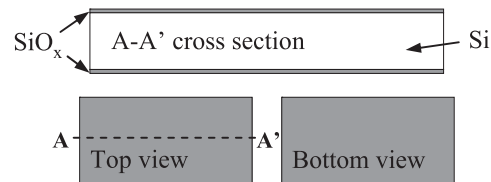

(2) Si etching with TMAH

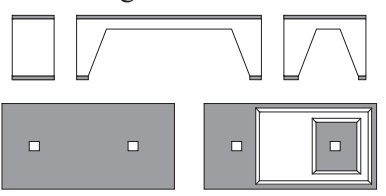

(3) Photoresist patterning for lift-off

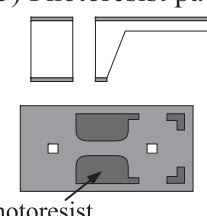

Photoresist

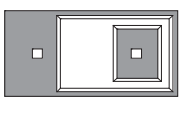

(4) Au-Sn sputtering

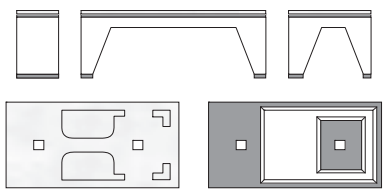

(5) Lift-off

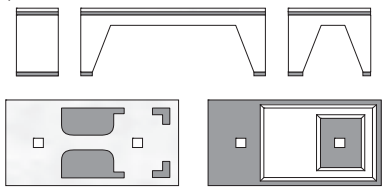

(6) $\mathrm{Si}$ and $\mathrm{SiO}_{\mathrm{x}}$ etching

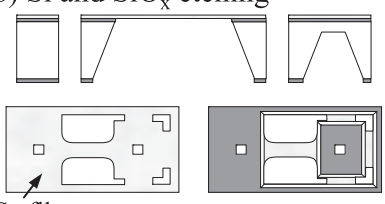

$\mathrm{Au}-\mathrm{Sn}$ film

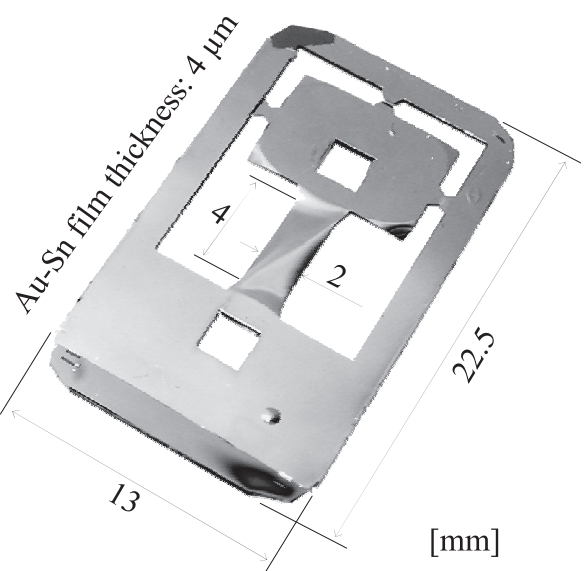

Fig. 1. Process flow for fabricating Au-Sn film specimen for tensile and creep tests and photograph of specimen.

oxidation on both sides of the wafer. After the wafer was diced to form strip chips measuring $13 \times 22.5 \mathrm{~mm}^{2}$, two square holes for fixing were simultaneously made on both sides of the chip by anisotropic wet etching with $20 \%$ tetramethyl ammonium hydroxide (TMAH) solution at $363 \mathrm{~K}$, and then the Si portion beneath the gauge section was also etched. A UV thick photoresist, SU-8, was used to form an inverted specimen pattern. A 4- $\mu \mathrm{m}$-thick Au-Sn solder film was deposited onto the photoresist pattern by magnetron sputtering, and then the pattern was removed to fabricate the gauge section of the Au-Sn film specimen by the lift-off technique. Annealing the Au-Sn film at $516 \mathrm{~K}$ for $2 \mathrm{~h}$ was carried out for the stabilization of film structure and its crystallinity, as described in the 
previous section. Finally, both $\mathrm{SiO}_{x}$ and $\mathrm{Si}$ layers on the entire surface of the chip were removed.

The specimen consisted of a specimen gauge section made of $\mathrm{Au}-\mathrm{Sn}$, hooking holes on Si grip ends, and a frame. ${ }^{(5)}$ The gauge section of $4 \mathrm{~mm}$ length, $2 \mathrm{~mm}$ width, and $4 \mu \mathrm{m}$ thickness had a fillet section for reducing stress concentration during testing. In finite element analysis (FEA), by applying a compulsory displacement of $1 \%$ gauge length to the entire specimen model, the longitudinal elastic strain at the straight part was calculated to be $0.617 \%$. This is because elastic deformation definitely occurs at not only the parallel portion but also the fillets on both ends of the gauge section. The trend of strain reduction depends on specimen shape only, irrespective of the mechanical properties input into FEA. Thus, the elongation in the gauge section can be estimated to be 0.617 times the total elongation of the specimen if the elongation of the entire specimen is measured accurately during the test. ${ }^{(6)}$ This correction works well in the elastic deformation range, but not in the inelastic range. In this study, the XRD tensile test was conducted within only the elastic deformation range of Au-Sn solder films. Only specimens having dimensional tolerances within $\pm 5 \%$ for all dimensions were subjected to tensile testing.

\subsection{XRD tensile test setup}

Figure 2 shows the uniaxial tensile tester developed for film specimens. The tester is composed of a piezoelectric actuator, a load cell, a linear variable differential transformer (LVDT), specimen holders, and a heater. ${ }^{(5,6)}$ These components are placed in an actuator case with dimensions of $130 \times 80 \times 30 \mathrm{~mm}^{3}$. The actuator case has a lever for amplifying the actuator's displacement by a factor of five in the tensile direction.

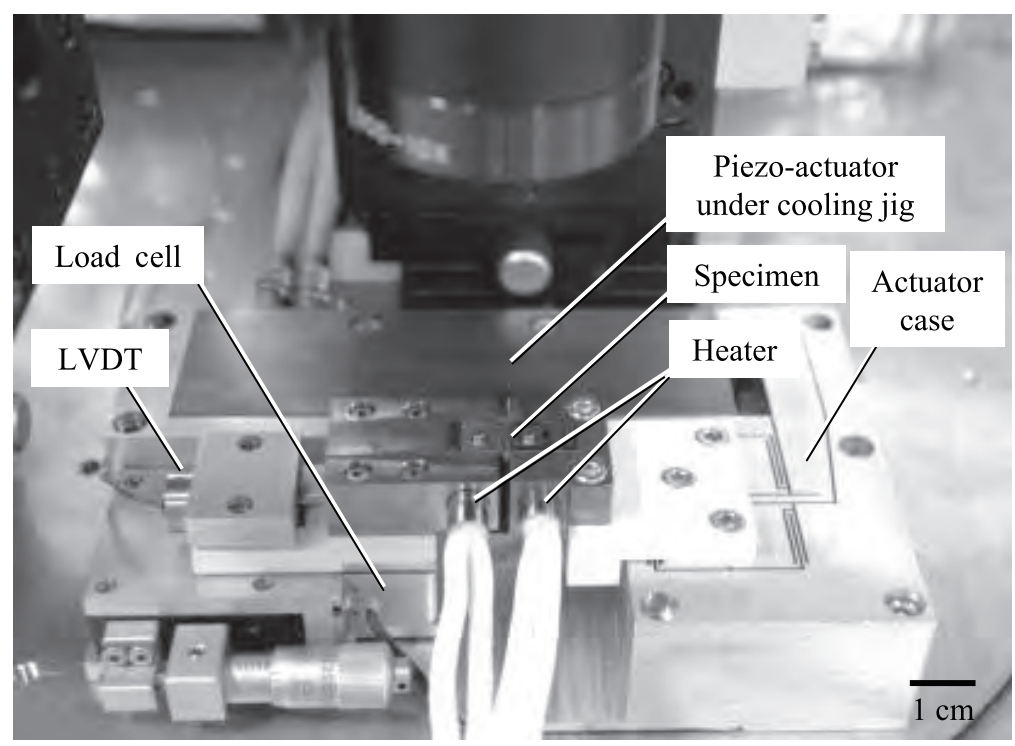

Fig. 2. Photograph of developed uniaxial tensile tester for film specimen. 
The actuator applies tensile force to the specimen that is hooked on specimen holders via hooking holes. The load cell has an accuracy of $0.10 \%$ of the full scale: $2 \mathrm{~N}$. The LVDT with a resolution of $3 \mathrm{~nm}$ measures the relative displacement between specimen holders, and is mounted on the actuator case and load cell. The heater, which produces a surface temperature of up to $973 \mathrm{~K}$, is embedded on specimen holders, and transmits heat to the specimen via the holder. During tensile testing, specimen surface temperatures ranging from RT to $373 \mathrm{~K}$ were precisely controlled by monitoring temperature using a thermocouple attached to both grip ends of the specimen.

As illustrated in Fig. 3, the tensile tester is mounted on an $x-y-z-\theta$ adjustable stage in a commercial XRD system (X'Pert MPD, Philips). In this test setup, the out-of-plane normal strain of a crystalline specimen can be measured directly with atomic resolution during tensile loading. If the scattering vector of the X-ray is normal to a crystalline specimen, the lattice spacing, $d$, in the out-of-plane direction is calculated using Bragg's law:

$$
d=\frac{\lambda}{2 \sin \theta}
$$

where $\lambda$ is the wavelength of the $\mathrm{X}$-ray $(\mathrm{Cu}, \mathrm{K \alpha}: 0.1541 \mathrm{~nm})$ and $\theta$ is the diffraction angle. As tensile force increases during the test course, the lattice spacing in the out-ofplane direction decreases, causing the XRD peak to shift toward a higher angle. Thus, measuring the peak angle for a certain interval of tensile force, which can be maintained

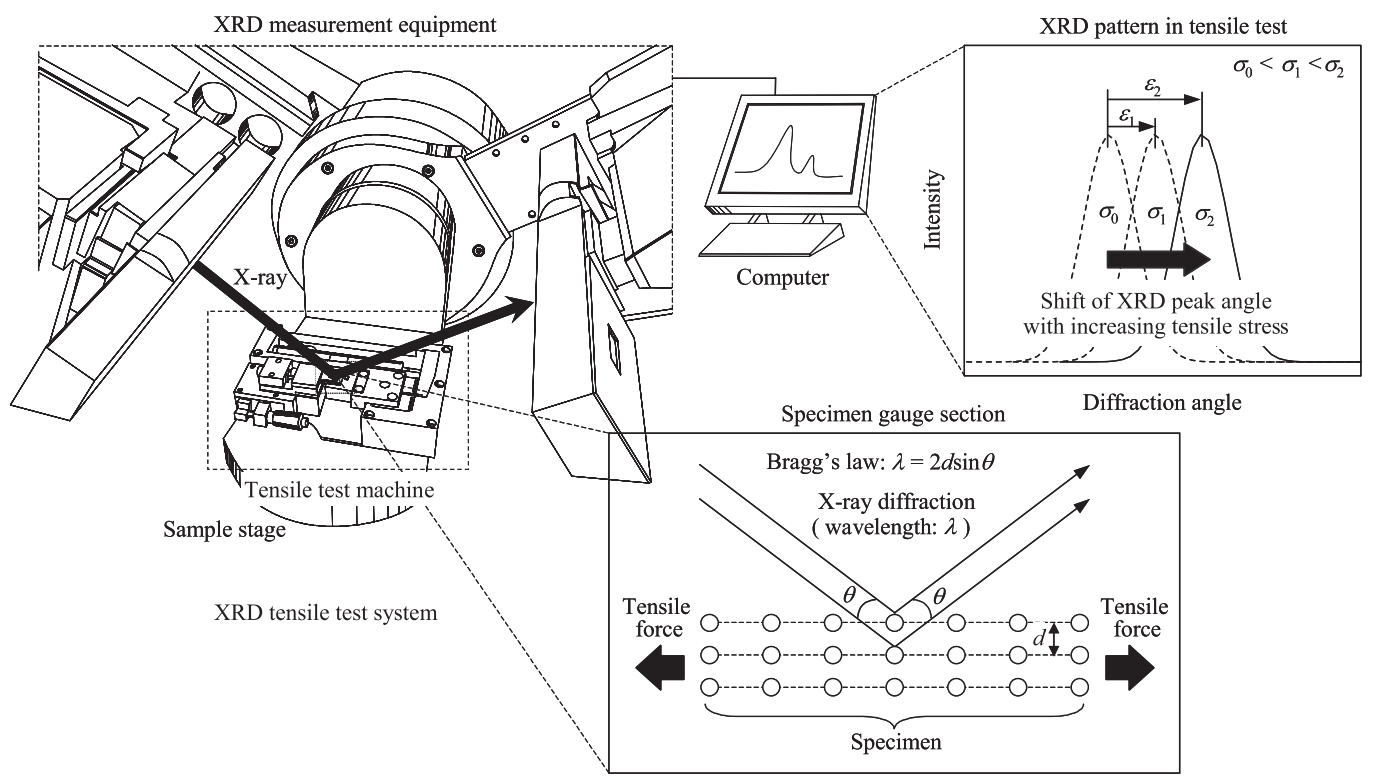

Fig. 3. Schematic of tensile testing with in situ X-ray diffraction analysis for evaluating out-ofplane strain of film specimen. 
using a feedback control program, enables us to determine the out-of-plane strain in a specimen. The Gauss function was employed when XRD data fitting was performed to determine the diffraction angle at the peak position. In this work, the theta-scanning time of a single XRD measurement was set to be $60 \mathrm{~s}$.

\section{Results and Discussion}

\subsection{XRD analysis}

Figures 4(a) and 4(b) show representative XRD curves around the AuSn (110) and $\mathrm{Au}_{5} \mathrm{Sn}(223)$ peaks at RT, respectively. The table in the figure indicates the increases in the spectrum peak angles of $\mathrm{AuSn}$ (110) and $\mathrm{Au}_{5} \mathrm{Sn}$ (223) with an increase in tensile stress. Although different XRD peaks corresponding to other orientations were observed in the XRD analysis, the intensities of these peaks were very low compared with those of both AuSn (110) and $\mathrm{Au}_{5} \mathrm{Sn}$ (223). When an initial tensile stress, that is, a preload, is applied to a Au-Sn specimen, the XRD peak angles are approximately 40.6 and 78.0 degrees, which correspond to typical angles of $\mathrm{AuSn}$ (110) and $\mathrm{Au}_{5} \mathrm{Sn}$ (223), respectively. As tensile stress increases, these peaks shift toward a higher angle. This indicates that the lattice spacings of the $\mathrm{AuSn}(110)$ and $\mathrm{Au}_{5} \mathrm{Sn}$ (223) planes, which lie parallel to the specimen surface, gradually decrease with increasing stress. Although the applied tensile
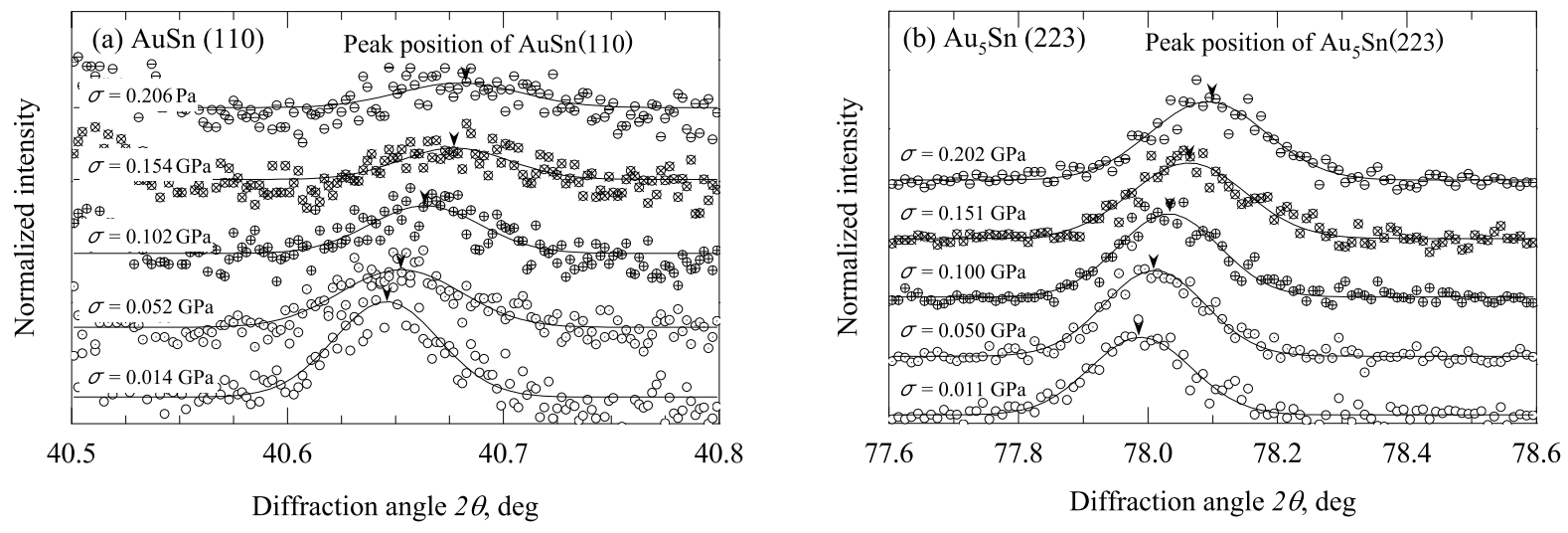

\begin{tabular}{c|c|c|c|c|c|c|c}
\hline \multicolumn{4}{c|}{ AuSn (110) } & \multicolumn{4}{c}{$\mathrm{Au}_{5} \mathrm{Sn}(223)$} \\
\hline $\begin{array}{c}\text { Tensile } \\
\text { stress }\end{array}$ & $\begin{array}{c}\text { Out-of- } \\
\text { plane strain }\end{array}$ & $\begin{array}{c}\text { Diffraction } \\
\text { angle }\end{array}$ & $\begin{array}{c}\text { Angle } \\
\text { increment }\end{array}$ & $\begin{array}{c}\text { Tensile } \\
\text { stress }\end{array}$ & $\begin{array}{c}\text { Out-of- } \\
\text { plane strain }\end{array}$ & $\begin{array}{c}\text { Diffraction } \\
\text { angle }\end{array}$ & $\begin{array}{c}\text { Angle } \\
\text { increment }\end{array}$ \\
\hline$\sigma[\mathrm{GPa}]$ & $\varepsilon_{z}[\%]$ & $2 \theta[\mathrm{deg}]$ & {$[\mathrm{deg}]$} & $\sigma[\mathrm{GPa}]$ & $\varepsilon_{z}[\%]$ & $2 \theta[\mathrm{deg}]$ & {$[\mathrm{deg}]$} \\
\hline \hline 0.01 & 0 & 40.64583 & 0 & 0.01 & 0 & 77.98889 & 0 \\
\hline 0.051 & -0.019 & 40.65248 & 0.008 & 0.051 & -0.023 & 78.01007 & 0.021 \\
\hline 0.101 & -0.042 & 40.66364 & 0.018 & 0.101 & -0.047 & 78.03235 & 0.043 \\
\hline 0.152 & -0.074 & 40.67735 & 0.032 & 0.152 & -0.079 & 78.06256 & 0.074 \\
\hline 0.203 & -0.094 & 40.68826 & 0.042 & 0.203 & -0.102 & 78.09282 & 0.104 \\
\hline
\end{tabular}

Fig. 4. XRD patterns around $\mathrm{AuSn}(110)$ and $\mathrm{Au}_{5} \mathrm{Sn}$ (223) peaks with increasing tensile stress at RT. 
stress is constant, the amount of peak shift per unit tensile stress in $\mathrm{Au}_{5} \mathrm{Sn}$ (223) is about 2.5 times larger than that in AuSn (110). This is related to the difference in peak angle between the crystal planes. From Bragg's law, since the XRD peak position of $\mathrm{Au}_{5} \mathrm{Sn}$ (223) is higher than that of AuSn (110), an increase in the peak angle per unit strain in $\mathrm{Au}_{5} \mathrm{Sn}$ (223) is certain to be larger than that in AuSn (110). This fact suggests that higher-angle peaks give better resolution in out-of-plane strain calculation. The different peaks may provide different elastic responses if the grain size is comparable to the specimen size. However, in fact, the Au-Sn specimen size would be much larger than the grain size that is thought to be on the submicron scale, although grain size has not been measured experimentally. We assumed, therefore, that the effect of the difference in XRD peak on the elastic response of a micron-sized specimen could be ignored, and employed only $\mathrm{Au}_{5} \mathrm{Sn}$ (223) peaks for out-of-plane strain calculation in the Au-Sn film specimen. At 323 and $373 \mathrm{~K}$, similar trends were observed between the $\mathrm{Au}_{5} \mathrm{Sn}$ (223) peak and that at RT, although the data are not provided here.

\subsection{Stress-strain relation}

Figure 5(a) shows the representative tensile stress-strain relationship obtained from XRD tensile testing at RT. The solid line is plotted as a reference to the revised longitudinal strain, that is, 0.617 times the strain obtained from LVDT measurement. The open and closed plots represent out-of-plane strains from XRD analysis at $\mathrm{Au}_{5} \mathrm{Sn}$ (223) and AuSn (110), respectively. The specimen was tensioned within only the elastic deformation range. The tensile stress-longitudinal strain relationship is linear in the stress range below $0.15 \mathrm{GPa}$. Above $0.15 \mathrm{GPa}$, it exhibits a step shape. The step shape originates from the creep deformation of the Au-Sn solder film. The creep deformation occurred when tensile stress was kept constant using a feedback control program for out-of-plane strain measurement by XRD analysis. The amount of creep deformation gradually increases with an increase in the tensile stress applied. The slope of the dashed line, which is drawn by eliminating the creep effect from the solid line, provides a Young's modulus of $51.3 \mathrm{GPa}$. This value is approximately $24 \%$ lower than the electroplated Au-Sn bulk value. ${ }^{(4)}$ On the other hand, a linear relationship between tensile stress and out-of-plane strain was obtained. The out-of-plane Poisson's ratio corresponding to the ratio of the out-of-plane strain of $\mathrm{Au}_{5} \mathrm{Sn}$ (223) to the longitudinal strain is found to be 0.288 , which is almost the same as that of AuSn (110). This agreement indicates that the effect of the difference in crystal orientation determined by the XRD analysis of the out-of-plane strain is small. The measured Poisson's ratios are almost $30 \%$ smaller than the bulk value. ${ }^{(4)}$

Figures 5(b) and 5(c) show the stress-strain relationships at 323 and $373 \mathrm{~K}$, respectively. As temperature increases, the step shape of the solid lines that were indicated at RT becomes clearer. The plateau regions in the stress-strain relationships at 323 and $373 \mathrm{~K}$ are, respectively, approximately 5 and 70 times larger than that at RT. The amount of creep deformation increases with increasing temperature and tensile stress. The Young's moduli at 323 and $373 \mathrm{~K}$ are 50.6 and $39.3 \mathrm{GPa}$, respectively, which are smaller than that at RT. On the other hand, the linear relationship between out-ofplane strain and tensile stress is observed regardless of temperature. It is considered 

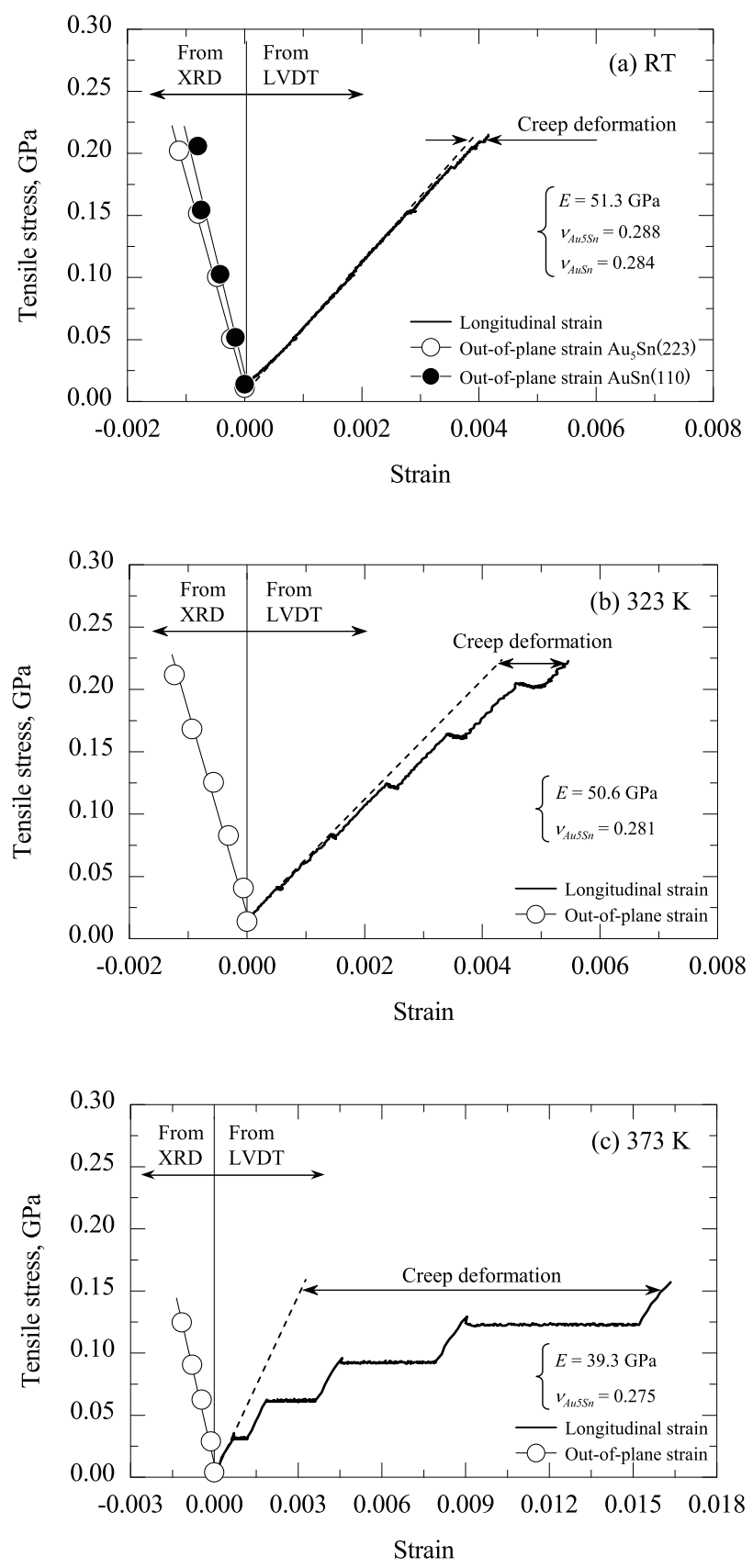

Fig. 5. Tensile stress-strain relationships of AuSn solder films evaluated by XRD tensile test at RT, 323, and $373 \mathrm{~K}$. 
that the effect of creep deformation on XRD analysis is small. The Poisson's ratios at 323 and $373 \mathrm{~K}$ are 0.281 and 0.275 , respectively, which are almost the same as that at RT. The Poisson's ratio exhibited none of the temperature dependence that was clearly observed in the Young's modulus. The relationship between the Young's modulus, $E$, and the temperature, $T$, can be expressed as

$$
E=-0.16 T+100.7 \text {, }
$$

where the units of $E$ and $T$ are $\mathrm{GPa}$ and $\mathrm{K}$, respectively.

\subsection{Creep test result}

From the XRD tensile test results, creep deformation was found to definitely occur in Au-Sn solder films. In order to evaluate creep deformation behavior, a creep test was carried out. Figure 6 shows the representative creep test result of the Au-Sn solder film obtained at $353 \mathrm{~K}$. The solid line is indicative of the creep strain curve, and the open plots indicate the creep rate curve. The creep strain curve is clearly divided into three regions of transient, steady-state, and tertiary creeps. At the beginning of the test, creep strain increases markedly because the Au-Sn film deforms rapidly, whereas strain rate decreases drastically in a short time. In the steady-state region, a linear relationship between creep strain and time is observed. Creep strain rate reaches its minimum of around $0.24 \% / \mathrm{h}$, and remains approximately constant for $23 \mathrm{~h}$. Approximately $30 \mathrm{~h}$ after the test start, creep strain rate rapidly increases, and then the film fails when the test time exceeds $34 \mathrm{~h}$. The total creep strain until failure is $8.8 \%$, which is approximately 8 times larger than that of the Au-Sn bulk value. ${ }^{(4)}$ The Au-Sn bulk typically consists of many grains on the micron scale, whereas the sputtered Au-Sn film tested is thought to have a columnar structure. In the creep test, tensile force is applied to the film along the inplane direction of the specimen, which corresponds to the orthogonal direction relative to

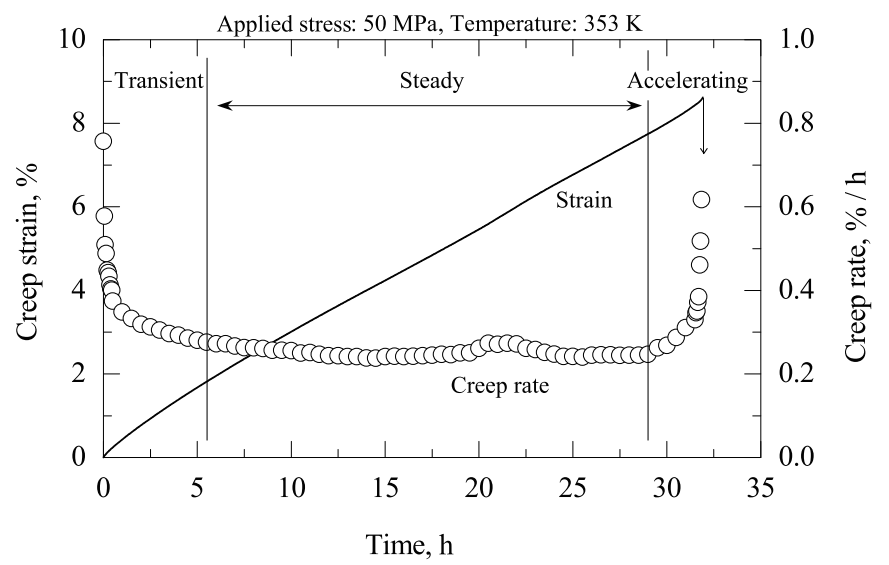

Fig. 6. Relationships between creep strain, creep rate, and time obtained in creep test on AuSn solder film. 
the columns; therefore, grain boundary sliding is easily induced, leading to a large creep strain in the film.

Figures 7(a)-7(c) show representative creep curves of the Au-Sn solder films at 323, 353 , and $373 \mathrm{~K}$, respectively. In Fig. 7(a), at a constant tensile stress of $50 \mathrm{MPa}$, creep strain is found to be approximately $0.2 \%$ at $20 \mathrm{~h}$ after the stress application. The creep strain for a $20 \mathrm{~h}$ duration reaches $1.6 \%$ as constant stress increases to $100 \mathrm{MPa}$. These creep deformation behaviors increase in intensity markedly with temperature increase, as shown in Figs. 7(b) and 7(c). At the highest temperature, some of the specimens even failed within an hour. This indicates that, in the Au-Sn films, the mobility of dislocations or grain boundary sliding that contributes to creep deformation would be more effectively activated at a higher temperature under a higher-stress condition.

Figure 8 shows the relationship between steady-state creep strain rate and constant tensile stress in the creep test. Steady-state creep strain rate was defined as the strain rate in the plateau region shown in Fig. 6. Steady-state creep strain rate linearly increases with increasing stress and temperature. The linear relationship in the logarithmic
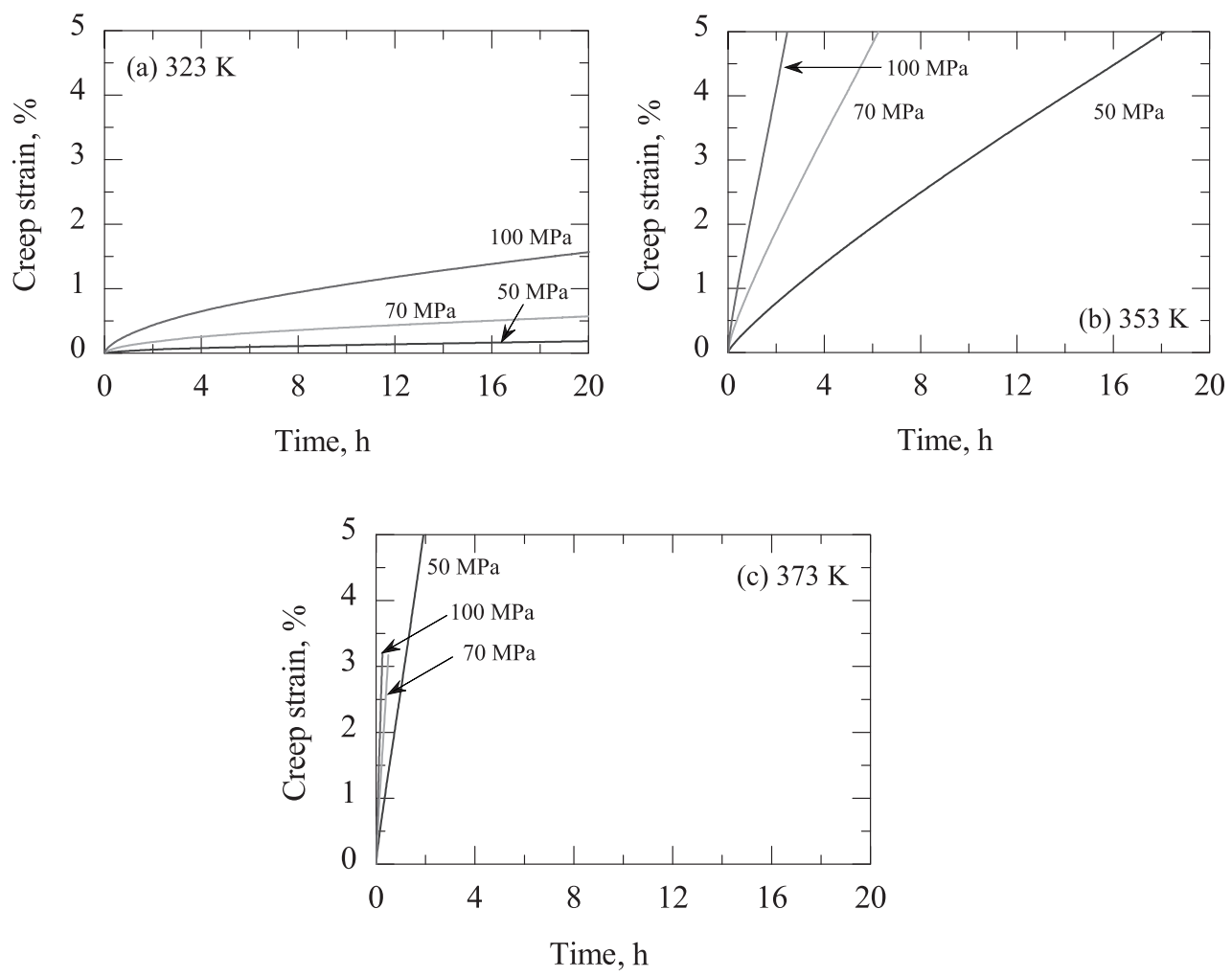

Fig. 7. Typical creep curves for AuSn solder films when constant tensile stresses were applied at 323,353 , and $373 \mathrm{~K}$. 


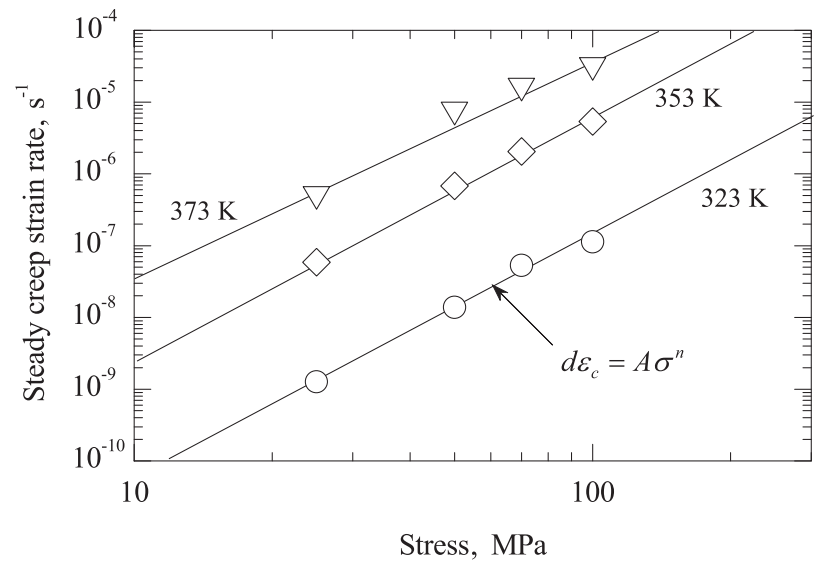

Fig. 8. Relationship between steady-state creep strain rate and constant tensile stress applied in creep test.

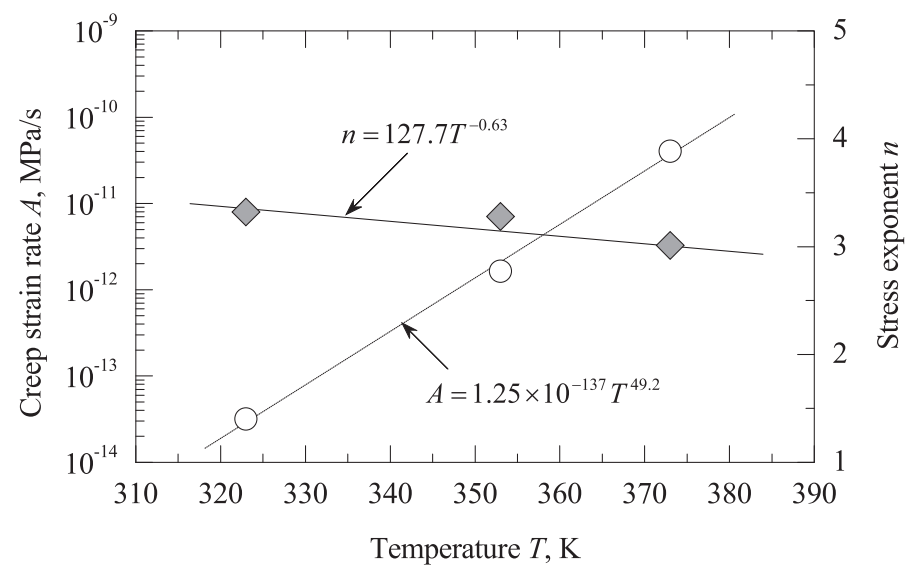

Fig. 9. Creep strain rate and stress exponent parameters as function of temperature.

diagram indicates that the steady-state creep constitutive equation of Norton's rule is applicable to the Au-Sn solder films employed. Norton's law takes the form

$$
\dot{\varepsilon}_{c 2} \equiv \frac{\mathrm{d} \varepsilon_{c 2}}{\mathrm{~d} t}=A \sigma^{n}
$$

where $\dot{\varepsilon}_{c 2}$ is the steady-state creep strain rate, $\varepsilon_{c 2}$ is the steady-state creep strain, $A$ is the creep strain constant, and $n$ is the stress exponent. $A$ and $n$ are temperature-dependent material constants, which can be determined by fitting the creep rate-stress relationship in Fig. 8.

Figure 9 shows the creep constants as a function of temperature. Creep strain constant shows a linear increase with temperature, whereas the stress exponent is 
inversely proportional to temperature. The creep constants are given as

$$
\begin{gathered}
A=1.25 \times 10^{-137} T^{49.2}, \\
n=127.7 T^{-0.63} .
\end{gathered}
$$

The equations can be used for the structural design of Au-Sn film bonded microstructures where steady-state creep deformation has to be considered.

\section{Conclusions}

In this study, XRD tensile and creep tests were carried out to measure the mechanical properties of Au-20 wt.\% Sn solder films deposited by dual-source magnetron sputtering. In the XRD tensile test, an XRD peak shift to a higher angle with increasing tensile stress was clearly observed, which enabled us to estimate the out-of-plane Poisson's ratio of the film. The tensile stress-longitudinal strain relationship showed a step shape originating from the creep deformation in the film. The measured Young's modulus and Poisson's ratio at RT were $51.3 \mathrm{GPa}$ and 0.288 , respectively. The Young's modulus decreased with temperature increase, whereas the Poisson's ratio showed no temperature dependence.

In the creep test, all the Au-Sn solder films showed transient, steady-state, and tertiary creep behaviors. The total creep strain at the creep rupture point was larger than that of Au-Sn bulk. The steady-state creep behavior was fitted by Norton's law, and creep parameters for constructing a constitutive equation were obtained. The obtained parameters would be useful within the intermediate temperature range tested when a structural design including a Au-Sn-film-bonded microstructure is carried out.

\section{References}

1 L. Shi, Z. Qian and S. Liu: ASME 99-IMECE/EEP-29, Vol. 1 (1999).

2 S. Sommadossi, J. Huici, P. K. Khanna, W. Gust and E. J. Mittemeijer: Z. Metallkd. 93 (2002) 496.

3 S. Kikuchi, M. Nishimura, K. Suetsugh, T. Ikari and K. Matsushige: Mater. Sci. Eng. A319321 (2001) 475.

4 F. G. Yost, M. M. Karnowsky, W. D. Drotning and J. H. Gieske: Metall. Trans. 21A (1990) 1885.

5 T. Namazu, S. Inoue, H. Takemoto and K. Koterazawa: IEEJ Trans. Sens. Micromach. 125 (2005) 374.

6 T. Namazu, A. Hashizume and S. Inoue: Sens. Actuators, A 139 (2007) 178.

7 J. A. Ruud, D. Josell and F. Spaepen: J. Mater. Res. 8 (1993) 112.

8 P.-O. Renault, K. F. Badawi, Ph. Goudeau and L. Bimbault: J. Appl. Phys. 10 (2000) 91.

9 K. F. Badawi, P. Villain, Ph. Goudeau and P.-O. Renault: Appl. Phys. Lett. 80 (2002) 4705.

10 D. Faurie, P.-O. Renault, E. Le Bourhis and Ph. Goudeau: Acta Mater. 54 (2006) 4503.

11 T. Namazu and S. Inoue: Fati. Fract. Eng. Mater. Struct. 30 (2007) 13. 